\title{
Low Frequency Characteristic Analysis of Voltage Mode Boost Converter
}

\author{
Yan Luo a and Hongmei Xu ${ }^{b^{*}}$ \\ Institute of Engineering Yanbian University, Yanji, China \\ aluoyan015@163.com,bhmxu@ybu.edu.cn \\ *The corresponding author
}

Keywords: Boost converter; Modeling; Simulink; Low frequency

\begin{abstract}
Boost converter circuit model is built by Simulink, through the analysis of the boost switch converter working conditions and parameters of frequency are adjusted, boost switching converter output characteristic changing with frequency and typical working condition corresponding parameter selection of boost converter can be obtained. Otherwise, the methods in the paper obtained provide reference for design other types of switching converter.
\end{abstract}

\section{Introduction}

Voltage control mode boost converter is widely used in communication, military, computer, instruments and meters, etc [1-2]. Practical application results show that the switching converter can appear low frequency oscillation phenomenon in a fixed parameter range, which will not only affect the stability of the system, but also affect the output voltage conversion efficiency [3-5]. In the converter design stage, the analysis of phenomena conditions and physical mechanism has practical guiding significance for designing a stable and reliable power supply system. Previous studies for the switching converter are based on discrete model and small signal model of state space average method [6-8]. These analysis methods are not variable frequency, so the influence of frequency changes on the switching converter output characteristics cannot be obtained [9-10]. Voltage-mode control boost converter as an example will be taken, and Simulink model of switching converter will be established in the paper, the frequency parameters of the switch converter operating characteristics will be discussed in detail, so as to provide the basis for the design of other converters.

\section{Discrete Model of Voltage Controlled Boost Converter}

Booster switch converter is a kind of circuit structure, which operates by transforming low amplitude direct current input voltage into high amplitude output voltage to meet the project needs. Its schematic diagram is shown in Fig.1. The switch of the switching tube is decided by output voltage $V_{e}$ of the voltage operational amplifier and sawtooth signal $V_{\text {ramp }}$, if $V_{e}>V_{\text {ramp }}$, comparator output high level, switching tube $\mathrm{S}$ conduction; if $V_{e}<V_{\text {ramp }}$, comparator output low level, switching tube $S$ cut off. The mathematical expression of sawtooth wave $V_{\text {ramp }}$ signal is obtained as follows

$$
V_{\text {ramp }}=V_{L}+\left(V_{H}-V_{L}\right)(t / T \bmod 1)
$$

Where $V_{L}$ is the lower limit of sawtooth, $V_{H}$ is the upper limit of sawtooth, $V_{m}=V_{H}-V_{L}$ is the peak-to-peak value, $T$ is the sawtooth wave cycle, $f=1 / T$ is the sawtooth wave frequency. The concrete working principle as shown in Fig.2. 


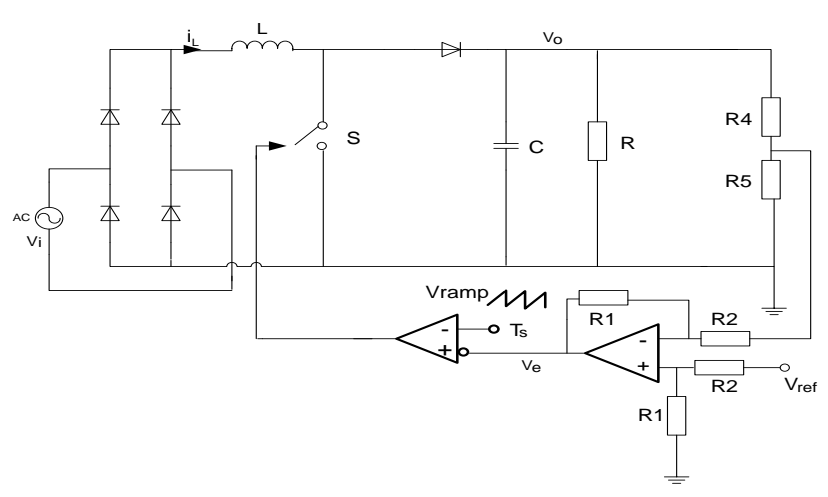

Figure 1. Boost converter schematic diagram

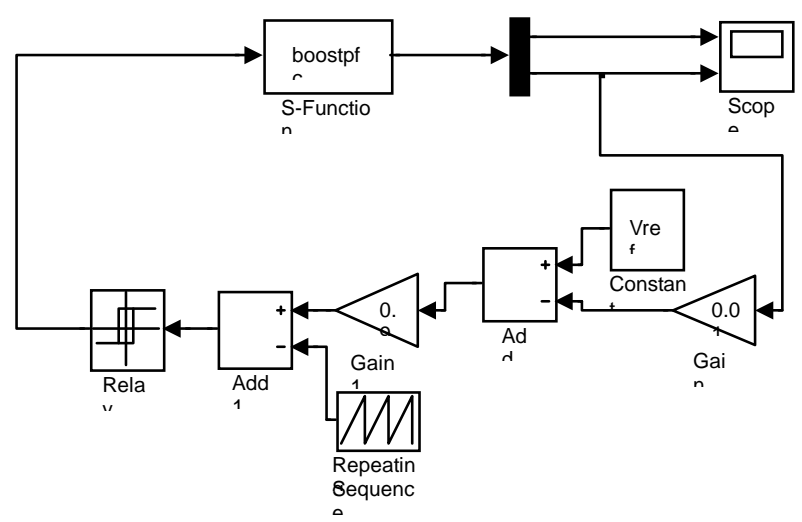

Figure 2. Simulink module diagram of the boost converter

Simulink module diagram of the voltage-mode controlled boost converter is shown in Fig. 2.

\section{Characteristic Analysis of the Circuit Operation}

Circuit does not exit low-frequency fluctuation, when voltage-mode controlled boost converter is in inductor current discontinuous mode. So the examples presented in the paper are used in the inductor current continuous mode. Command mode is used to assign parameter variable. The input voltage is $5 \mathrm{~V}$, the reference voltage is $3 \mathrm{~V}$, the step length is set to $\mathrm{Ts} / 10$, time is set to $0.05 \mathrm{~s}$.

Stable Condition. The component values are used as: $R=10 \Omega ; L=57 e-5 H ; C=40 e-5 F$; $f=3 e-3 H z$, the corresponding circuit working condition as shown in Fig.3. The inductor current and output voltage enter a stable working condition after several transient oscillations.
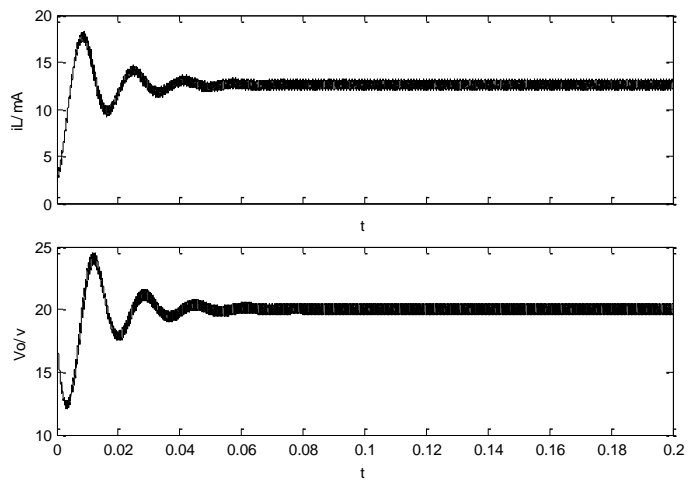

Figure 3. Stable working state 
Circuit Characteristic Analysis. Transform circuit component values that used give $R=300 \Omega ; L=30 e-6 H ; C=30 e-6 F$. When the frequency decreases, inductor current appears pulse waveform, output voltage shows ripple, and output voltage ripple coefficient increases with the frequency decline, the waves are shown in Fig. 4.

Frequency Effect on Circuit Characteristics. In order to further observe circuit features on frequency changes, circuit component values are given for test as follows: $V_{i}=5 \mathrm{~V} ; V_{\text {ref }}=3 \mathrm{~V}$; $R=10 \Omega ; L=80 e-5 H ; C=5.6 e-3 F$; this moment, inductor current and output voltage should be unlimited increase, but due to the effect of unilateral conduction of the diode, inductor current cannot be infinite, and eventually formed the oscillation frequency is lower than the switching frequency of the low-frequency oscillation phenomenon. As can be seen from the Fig. 5, low-frequency wave phenomenon become more and more obvious with the frequency decline.
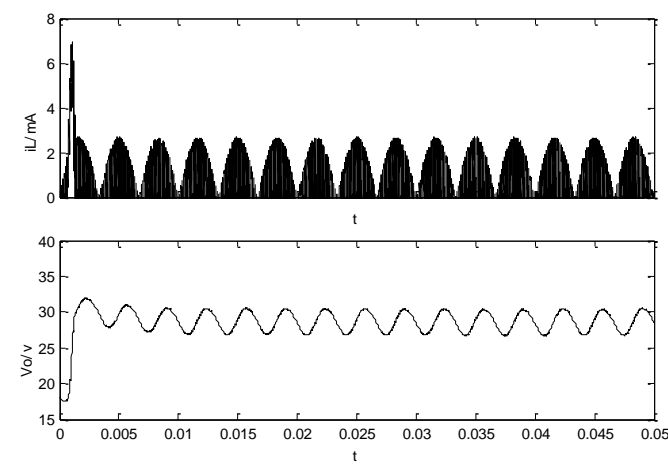

Figure 4. Oscillation working states $(\mathrm{f}=150 \mathrm{~Hz})$

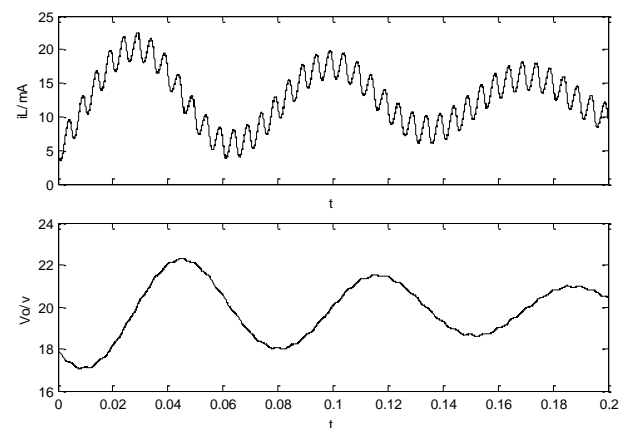

Figure 5. Low-frequency oscillation phenomenon $(\mathrm{f}=100 \mathrm{~Hz})$

\section{Conclusions}

The examples presented in the paper were based on voltage-mode controlled boost switching converter, simulation method is used to get the circuit working characteristic in the inductor current continuous mode. The analytical and experimental results demonstrate that the size of the switching frequency has important influence on voltage-mode controlled boost converter output characteristics. The waveform shows that different parameters corresponding fine working process and switch converter output characteristic can be outputted. When other circuit parameters specified, voltage control model of the boost converter prone to low frequency bifurcation and expressed in the form of low frequency oscillation with the frequency decrease.

\section{Acknowledgements}

The research work is supported by Natural Science Foundation of the Education Department of Jilin Province under Grant No. 2015-11 and Natural Science Foundation of Yanbian University under Grant No. 2012800-602014044 and Scientific Research Starting Foundation of Yanbian University 
under Grant No. 2012800-602014093.

\section{References}

[1] S. De, P.S. Dutta and S. Banerjee. Torus destruction in a nonsmooth noninvertible map. Physics Letters A, Vol. 37 (2012) No.6, p.400.

[2] S. Parui, S. Banerjer. Bifurcations due to transition from continuous conduction mode to discontinuous conduction mode in the boost converter. IEEE Transactions on Circuits and Systems-I: Fundamental theory and applications, Vol. 50 (2003) No.11, p.1464.

[3] L.H. Nguyre, K.S. Hong. Hopf bifurcation control via a dynamic state-feedback control. Physics Letters A, Vol. 37 (2012) No.6, p.442.

[4] Z.T. Zhusubaliyev, O.O. Yanochkina and E. Mosekilde. Torus bifurcation mechanisms in a DC/DC converter with pulsewidth-modulated control. IEEE Transactions on Power Electronics, Vol. 26 (2011) No.4, p.1270.

[5] D. Giaouris, S. Banerjee, O. Imrayed, K. Mandal, B. Zahawi and V. Pickert. Complex interaction between tori and onset of three-frequency quasi-periodicity in a current mode controlled boost converter. IEEE Transactions on Circuit and Systems-I, Vol. 59 (2012) No.1, p.207.

[6] Z.T. Zhusubaliyev, E. Mosekilde. Torus birth bifurcations in a DC/DC converter. IEEE Transactions on Circuits and Systems-I:Regular Papers, Vol. 53 (2006) No.8, p.1839.

[7] H. Zhang, X.P. Yang, X.K. Ma and B. He. Analysis of limit cycle behavior in DC-DC boosts converters. Nonlinear Analysis: Real World Applications, Vol. 25 (2012) No.2, p.83.

[8] J. Laugesen, E. Mosekilde and Z.T. Zhusubaliyev. Bifurcation structure of the C-type period-doubling transition. Physica D, Vol. 24 (2012) No.1, p.488.

[9] W.P. Zhong, M. Belic. Resonance solitons produced by azimuthal modulation in self-focusing and self-defocusing materials. Nonlinear Dynamics, Vol. 73 (2013) No.4, p.2091.

[10]J.L. Li, J.Y. Lin. An algorithm of local prediction for chaotic sequences with variable frame length. Journal of Electronics, Vol. 29 (2012) No.3, p.345. 